\title{
Merging Graphic Design and Multimedia Features in Digital Interactive eBook for Tourism Purposes
}

\author{
Lee, L. S. ${ }^{1}, \mathrm{Ng}$, G. W. ${ }^{2}$, Ooi, J. Z. ${ }^{3}$, Oon, Y. B. ${ }^{4}$ \\ ${ }^{I}$ Faculty of Creative Arts and Design, Universiti Malaysia Sarawak \\ 94300 Kota Samarahan, Sarawak, Malaysia \\ ${ }^{1} 150201760$ siswa. unimas.my \\ ${ }^{2}$ Faculty of Cognitive Sciences and Human Development, Universiti Malaysia Sarawak \\ 94300 Kota Samarahan, Sarawak, Malaysia \\ ${ }^{2}$ gwngefcs.unimas.my \\ 3edwinwin91@gmail.com \\ ${ }^{4}$ yboonefcs. unimas.my
}

\begin{abstract}
Tourism is becoming increasingly popular in many parts of the world. However, a visitor in a foreign country may feel anxious if information is display in a foreign travel guidebook. A phenomenon where tourist may face arbitrarily representation of an object by viewing the pictures and description has led to this paper entitle merging graphics design and multimedia features in digital interactive eBook for tourism purposes. The advantages of interactive eBook offered by computational technologies should widely be implemented instead of just adhere to paper book metaphor. This study aims to develop an eBook supported with active and interactive contents for tourism purposes.
\end{abstract}

Keywords- Graphic design, multimedia, digital interactive, eBook

\section{INTRODUCTION}

Tourism has started to become one of the common hobbies and travelling has becoming a part of to-be-done thing in modern lives [1]. According to [2], travel guidebook not only contains information and resources pertaining destination of interest which is normally includes landmarks, transportation, accommodation, and food but also it can act as a tool for education and improving tourist understanding the destination or the culture before heading to the destination. The purpose of this study is to develop an eBook that include image slideshow, video and 3D object using ePUB creator.

\section{PROBLEM STATEMENT}

Although most of the readers may face arbitrarily representation of a specific object by just viewing the pictures and description, ePubs nowadays able to bring a clearer picture to describe the detail of the object or products. Human visual systems are built to perceive the shapes of 3D surfaces [3]. Arbitrary representation happen when reader learning 3D object by using 2D representation. For example, Mathematics text book described the features the geometry by providing the picture and description. Most of the students may easily be confused and unable to figure out the real structure of the geometry due to $2 \mathrm{D}$ visualization which is unable to give accurate detail.

\section{RESEARCH OBJECTIVES}

The main objective of this research is to develop an eBook supported with active and interactive content, which enable users to gain new experience and knowledge of eBook.

\section{LITERATURE REVIEW}

\section{A. eBook}

As highlighted by [4], electronic book (eBook) is an electronic version of a traditional paper print book. At the beginning eBook were defined as paper books converted to a digital format which using scanner or typing in order to allowed them to be displayed on computer. As the times goes by, the definition of eBook has been extended, eBook must be included book title that are available online, can be read or send by a portable electronic devices or through e-mail. Other than that, the eBook also can be downloaded onto computer. For example, text rich education eBooks can be enhanced the reader's level of understands by adding them dynamic, interactive visuals.

Currently, eBooks has been evolved from text and images to multimedia assets. Users are able to customize their eBook through software such as changing text size, adding bookmarks, and highlights important texts.

According to [5], the improvement of eBook has taken few aspects into consideration so that the eBook will excel better than the others. One of the aspects to be taken for eBooks is weight. The weight refers to the size of the file. The smaller the file, the better it is as it enables devices to load the file almost instantly. However, high quality file or pictures inside the eBook may sometime cause the eBook to have high weight, therefore, proper technique is essential to maximize the content and minimize the weight. Thus, a balance between adherence to the paper book metaphor and integration of the interactive power of computers is necessary to allow for a better appreciation of eBooks. 